Distributed leadership as administrative practice in Finnish early childhood education and care

\title{
Kangas, Jonna
}

2016-07

Kangas , J , Venninen , T \& Ojala , M 2016 , ' Distributed leadership as administrative practice in Finnish early childhood education and care ' , Educational Management Administration \& Leadership , vol. 44 , no. 4 , pp. 617-631 . https://doi.org/10.1177/1741143214559226

http://hdl.handle.net/10138/299957

https://doi.org/10.1177/1741143214559226

publishedVersion

Downloaded from Helda, University of Helsinki institutional repository.

This is an electronic reprint of the original article.

This reprint may differ from the original in pagination and typographic detail.

Please cite the original version. 


\title{
Distributed leadership as administrative practice in Finnish Early
}

\section{Childhood Education and Care}

\author{
Venninen, Tuulikki ${ }^{\text {a }}$ \\ Leinonen, Jonna ${ }^{\text {ab }}$ \\ Ojala, Mikko $^{\text {a }}$
}

\section{Introduction}

Well-educated and well-trained professionals are the key elements in providing high quality early childhood education and care (ECEC) and thus ensuring the most favourable cognitive and social outcomes for children (Sylva, Melhuish, Sammons, Siraj-Blatchford \& Taggart, 2010). Their findings could show that the quality of leaders and managers of ECEC services is related to their level of education and professional development. In addition, quality leadership had positive effects on children's short and long-term outcomes in both cognitive and social domains. An effective strategy for supporting leaders and managers can be consultation that provides opportunities to receive feedback. Although there is an increasing need for the development of leadership skills, leadership has received only marginal attention by ECEC researchers.

Even more important to the impact on child outcomes than the qualification of professionals per se is the ability to create and develop a high-quality pedagogical environment and practices (Taguma,

a) Department of Teacher Education, University of Helsinki

b) School of Education, University of Tampere

Contact: Tuulikki Venninen, tuulikki.venninen@helsinki.fi 
Litjens \& Makowiecki, 2012; Venninen, Leinonen, Ojala \& Lipponen, 2012). When high quality of ECEC is considered important, it requires the distribution of responsibilities and power between different organizational levels, where trust between the director and the staff is crucial (Burke, Sims, Lazzara \& Salas, 2007). In addition, the relationship between the director and the employee is studied. It would also be important to investigate the relationship between the workers (Tse, Dasborough, \& Ashkanasy, 2008).

In recent years, researchers and developers have been increasingly interested in distributed leadership(Mehra Smith, Dixon \& Robertson, 2006; Dalli, 2008) because the current working environments are so complex and challenging that a single leader or a team cannot handle them alone (O'Connor \& Day, 2007). In the educational context, the institutional culture, which includes the basic assumptions, values and artefacts of working and sharing power, has an important role in empowering members of culture (Schein, 1985). There is not much research on distributed leadership in early childhood education, especially among different organizational levels. In this study, the personnel as well as the director are seen as constructing and being able to take leadership. In the educational context, the institutional culture, which includes the basic assumptions, values and artefacts of working and sharing power, has an important role in empowering members of the culture (Schein, 1985).

Compared with other countries, Finland has high qualifications for ECEC teaching staff; participation in professional development is mandatory and the recommended maximum number of children per educator is among the lowest in the OECD. Although Finnish ECEC teachers are trained in management and planning during their initial education and in-service training is available to them, Finland, among many other OECD countries, has recognized a need for further leadership development in the ECEC area (Taguma et al., 2012). 
The focus of this paper is on the professional development of ECEC staff supported by professionals from different hierarchy levels within and between the organizations (educators, directors and administers) in Finland. This study is based on the research and developmental activities of the Development Unit of Early Childhood Education in the Helsinki metropolitan area between 2007 and2011. In this project, development was carried out by using reflective practices (Ojala \& Venninen, 2011). One important aim was to activate all key actors in the ECEC organization to develop their practices in close interaction with each other. Based on intensive follow-up and documentation, we will report how administrators and directors of day care settings working with educators in day care centres experienced their interaction in shared developmental activities.

\section{Changing ECEC administration}

When studying educational administration, Gunter (2012) has produced a multilayer analysis aiming to identify the key positions in knowledge construction. By using her typology, educational administration can be analysed in relation to production, processes, purposes, and practices. When analysing educational administration, two main approaches were identified: functional and socialcritical. Concerning processes in educational administration, the functional knowledge approach focuses on problem solving rather than social-critical problem posing. In relation to practices in educational administration, functional and social-critical knowledge constructions were identified. In active ECEC leadership, the interaction and communication between administrative leaders, practitioners, developers and researchers are important (Karila, 2010). In a transformative view, all actors are capable of language and action. They possess the capabilities of interpreting the world around them and act upon the information that they gather. Actors will and can make their own 
decisions and guide their actions if their relationship is not based on power. They give meaning to their own actions based on their life experiences and consciousness (Freire, 1998; Gomez, Racionero \& Sorde, 2010; Ojala, 2010). The terms 'power' and 'leadership' are intertwined. Their separation may be difficult because leadership can be defined as the use of power (Hackman \& Johnson, 2004). Leadership is often described as the balance of power between the leader and the employee (Northouse, 2007). Therefore, these concepts are closely linked, and determine each other (Hackman et al., 2004).

Distributed leadership can be considered through knowledge and power, where the development of knowledge building is viewed through power issues. This focus in distributed leadership can be described as social critical knowledge production. In their analysis of social critical knowledge production of distributed leadership, Gunter et al. (2013) offer three practical considerations of the distribution of leadership. First, ignore or equal the power transfer in the process; second, consider 'activity' in the process not from the structures of power, but as a personal attribute of a leader and the others, and finally forget the democratic aspects of leadership considering the human right to active agency. In consideration of power related issues, distribution of leadership is too often viewed only as a means to a smaller workload for individuals and better exchange for institutions, when it could be considered from the point of view of structural changes and democracy (Hartley, 2010b). In early childhood education institutions, democracy in power issues could be reached by reflection, and not only reflection by a leader, but shared reflective practices of the whole staff.

When developing ECEC leadership, theoretical thinking as well as research activities must be increased. In the critical approach, the role of communication is crucial (e.g., Gomez, Latorre, Sanchez \& Flecha, 2006; Gomez et al., 2010.) In this process, dialogue and interaction are 
important tools helping people to co-operate, reach agreement and work together in different forums.

In Finland, directors in early childhood education traditionally had led one day care centre and worked with children. Today most of them focus wholly on leadership and lead several units, because since the 1990s the smallest day care units have usually merged with larger ones. This was done to create multiunit organizations, i.e., distributed organizations in day care (Halttunen, 2009).

\section{Towards distributed leadership}

In leadership research, the idea of distributed leadership can be considered from functional perspectives. Gunter, Hall and Bragg (2012) state, that in a functional understanding of distributed leadership, the view is practical and the goal is to achieve 'better' working processes in everyday work. In the analysis of Gunter et al. (2013), functional also means that leadership is the property of one leader and it is his or her responsibility to actively share leadership and involve or empower others. When considering these two descriptions of distributed leadership, one may critically inquire, whether these 'others' have any responsibilities, or active roles in the distribution of leadership (Gunter et al., 2013)

In modern leadership research, such terms as distributed leadership, shared leadership, team leadership and democratic leadership are often used (Spillane, 2005). Spillane argues that the term distributed leadership is the most comprehensive when examining leadership. According to Spillane, Halverson \& Diamond (2004), leadership practices are not dependant on the expertise of individuals, but on that of the entire work community. 
Shared expertise is based on the idea that every member of a work community has more expertise than the others have in some area, but no one has all the expertise (Brown \& Campione, 1994). Some distinctive elements of the concept of distributed leadership can be discerned. Distributed leadership highlights leadership as an emergent property of a group or network of interacting individuals. Varieties of expertise are distributed across many people, not just a few. The idea that numerous, distinct, germane perspectives and capabilities can be found in individuals spread throughout an organization is related to the openness of the boundaries of leadership (Woods, Bennett, Harvey \& Wise, 2004). Ebbeck and Waniganayake (2003) question whether all of the individual functions of leadership should be one person's responsibility. Bryant (2003) found that it is possible for everyone to play a leadership role at different times and grow into this position.

Indeed, the degree of control and autonomy is a major variable in distributed leadership, e.g. how an organization constrains or enables different organizational members to take the initiative. A structural view of distributed leadership would conclude that the more the following elements are present in an institution, the more its leadership can be said to be distributed: the redistribution of internal institutional responsibilities, construction of a particular set of cultural norms, which encourage teachers to take risks, and the development of social relations characterized by high trust levels (Woods et al., 2004; see also Belbin, 2000).

According to Woods et al. (2004) not only issues of leadership are important in groups; the role of participants must also be considered. When participants are seen as having a problem-solving function, the staff who advises and monitors them operates in a facilitative rather than a controlling way, and the participants become more confident, so that they begin to intervene proactively in disputes to prevent them escalating. Those who exhibit distributed leadership in action also need to 
acknowledge and address the conflict. During the development of individual professionals, the staffs build a shared perspective and distribution across pedagogical activities (Spillane et al., 2004).

The distributed leadership needs wide communication. When fostering interaction and communication between agents, there is a need for transformative knowledge (Comez et al., 2010). This knowledge is seen as a dialogic knowledge based on inter-subjectivity to be reached between researchers and social actors. According to the critical communicative approach, egalitarian dialogue between the research community and social actors under research is crucial in order to achieve social justice. According to Freire (1998), many people possess critical consciousness and can find meaning in their situations and change them.

In the development project examined in this study, participants are not seen as individual educators or teams of educators, but rather as the day care centre's entire work community. The new practices will be created in the multi-professional development of working practices by utilizing the professional skills of educators with different areas of competence. However, the development of work in a day care centre is more challenging than in an ordinary work environment, because it is difficult to find free and available time to discuss development-related issues. Members of the work community only have a few moments during the day when they are free of responsibility for the children and can gather to discuss work methods or practices. Therefore, meetings are usually held with representatives from various groups and the information educators receive in them is based on second-hand knowledge received through those representatives (Rodd, 2004). This second-hand information increases the risk of misunderstanding and lowers the educators' rate of commitment to development programmes. 


\section{The context and methods of this study}

The Development Unit of Early Childhood Education of the Helsinki metropolitan area (the VKKMetro) was established in 2007. The University of Helsinki, the capital city of Helsinki and its three neighbouring municipalities (Espoo, Vantaa and Kauniainen) are the main actors. The area covers the living environment of one-fifth of all Finnish children under school age (Suomalainen lapsi, 2007). The Helsinki metropolitan area, more than the rest of the country, is subject to different kinds of challenges owing for example to increasing immigration (Ministry of the Interior, 2009). Therefore, educators working on early childhood education need to be able to respond to constant change, which is evident as new challenges, are directed toward them.

In this study, we describe the professional development towards distributed leadership in Finnish day care centres within the Helsinki metropolitan area, which has a total of 500 day care centres. VKK-Metro coordinates the development project. The objective is to collaborate on the development of day care pedagogy. A key framework in the development project consists of a network of 21 research day care centres. In the development process, the municipal administrator has aimed to enable educators in early childhood education to have a firm connection to research.

The aim of our study was to monitor the progress of professional development between educational administration and practitioners. In the process follow-up, conducted every two months, educators (alone or within the working team) provided information about the progress of the development process. So, the data was based on descriptions of reflective practices used in the development projects of each research day care centre. The researchers collected these reflections, analysed them to produce results, and then delivered this evidence to participants for utilization in reflection and 
further processing of working practices with the support of the mentor.

In addition, the researchers planned and implemented studies concerning municipal day care as a whole to acquire a broader picture of the issues related to the project period (see, Leinonen \& Venninen, 2012; Venninen et al., 2013). The research information too, was provided to the day care sector in the form of public lectures, workshops and reports after proper analysis and summary. The idea of effective intervention comes from evidence-based practice research where the development actions of professionals are considered in evidence-based interventions to find better working practices (Slavin, 2002). Process-type research related to a development project, where the results are utilized in the advancement of development of working practices, has been shown to be very significant, in both the identification and systematic development of working practices on early childhood education (Corter \& Pelletier, 2010).

This is a method of action research, where an important aspect is continuous interaction within the relationship among all the participants. The research methods need to respect these relationships and participants' shared understanding and differences in opinions about the evidence (McNiff \& Whitehead, 2006) This research method based on the idea of the changing and developing knowledge of the participants contains three key elements: multiplicity of knowledge, where several answers exists; the idea of knowledge as a created and shared object, not one that is discovered or pre-existing, and a tentative framework of modification and change (McNiff et al., 2006). Our data consisted of descriptions of process follow-up, interviews and learning diaries during the whole four-year project.

In the first phase of analysis, each description was sectioned in units of analysis and coded with a 'meaning of idea' title by using the Atlas TI 6.1 software. Some units of analysis were only wordlists; some descriptions went further by describing the different discussions. Secondly, the 
units of analysis were grouped to the categories depending on the context in which they were performed. In this phase, theoretical background theories were used for grouping the different forms of distributed leadership.

\section{Findings}

\section{Distributed leadership during the development project}

At the beginning of the development process, a mentor working in the early childhood education organization of the municipalities was designated for each research day care centre. In their fulltime positions, the mentors were development consultants, designers, development managers, and day care directors or experts on the higher organizational level. The mentors' activities in the research day care centres were included in their official job description. They met with the educators in the relevant research day care centre on a monthly basis and allocated one day per month for their work as a mentor. It was the duty of the mentors to motivate the educators to work on a development task of, that had been selected in collaboration, and to help educators see the phases of the development of working practices and the benefit gained from the development work. These solutions represented an effort to guarantee that the experience and knowledge accumulated during the development process remained in the organization. Another goal was to enable closer interaction amongst educators in the field as well as those in the administration of the relevant organization. The educators appreciated receiving assistance, such as inspiration and empowerment, from the mentors, as noted in next responses from participants. As Woods et al. (2004) note, it is important to see that participants have a problem-solving function and facilitate them to trust themselves. 
Distributed leadership as administrative practice in Finnish Early Childhood Education and Care

This is a unique experience in my work history: a total outsider comes, supports and helps us in our work. It used to be the case that people came to us with their demands. All this has already been rewarding, having these discussions (Group interview of staff).

... is an inspiring mentor who does not give direct advice, but makes you think about solutions for yourself. (Process follow-up by a team)

Mentors were supported in their duties through peer group activities. The mentors met monthly to agree on common, practical operating principles and to consider the terms, objectives and challenges in the operation of the network of research day care centres. The mentors also shared leadership in their peer group. Many mentors concluded that their method was occasionally close to work supervision. They also focused on reviewing the roles of the mentor and director. In their development processes of working practices, the educators highlighted tacit information that was easier to acknowledge and to conceptualize with the help of an outside mentor's questions and comments (e.g., Nonaka \& Takeuchi, 1995).

The input of the director of the day care centre was also significant for the success of the development of working practices. The director was in charge of pedagogic management at the research day care centre, which had to be in line with the development of the working practices undertaken during the project. It was the director's duty to arrange time for the reflective meetings of the participant teams or to enable participation in common research workshops. The educators also thought that emotion-based management is important, because encouragement and motivation were regarded as important duties for the director. In the next quotation, it becomes evident how the directors utilize natural settings in the day care centres to pay attention to the project. 
Distributed leadership as administrative practice in Finnish Early Childhood Education and Care

I have dealt with the project in the development discussions. (Process follow-up by a director)

I think I have deepened my pedagogical leadership when dealing with the subject concerning our project. VKK employees are more receptive and we speak the same language. The most difficult thing is to understand the different capabilities and competencies with employees and coordinate them to work with each other (Process followup by a director).

The director's job was also to inform the parents about the project. One educator noted, "The Director participates in the mentor meetings and takes the debate forward and she gives in a positive way information about it to the parents" (Process follow-up by a team). Halttunen (2009) points out that too often in Finland there is a lack of dialogue between the director and the staff about how different changes should be taken into account in organizations.

The directors managed their work communities according to the principles of distributed leadership and discussed common issues related to everyday education and life with their staff and in their own peer group; thus, distributed leadership took place on the upper level of the organization. Furthermore, the directors required peer support for their process of professional skills development. At their meetings, the directors of the research day care centres discussed issues related to the management and development of the work community, such as how to motivate educators to develop work practices, and how to work with or re-direct resistance to change. They shared their experiences about issuing feedback to work teams and individual educators. Everyday obstacles to the development of working practices, such as a shortage of workers or the problem of educator turnover, were also addressed. For many directors, the field of research evidences in early 
childhood education and their use in the development process opened up for the first time. One director noted, "We have been able to mirror our views and ideas, and together support staff in the development process" (Process follow-up by a director). Another stated that, "The Day-care centre director was responsible for the success of research and staff interest in the conservation and further development" (The interview of a director). As Gunter et al. (2013) note, in the functional view, leadership is the property of one leader to actively share and involve or empower others.

\section{Distributed leadership between mentors and directors}

The director and the mentor of the research day care centres constituted an important partnership. The director was responsible for the development of working practices in the research day care centre and the mentor's role was to support educators during the transformation of their own operating culture. As we can see in the next quotation, exercising the distributed leadership was not always easy. Participants from three organizational levels (educators, director and mentor) attended the meetings.

In our common meeting we noticed that the leader and the mentor did not have a uniform view of the basic issues... We hope that in the common meeting there will be a more structured execution so that the time is not spent arguing about. (Process follow-up by a team)

However, during the project, the director and mentor learned to share the goals and the key aspects of the development by using the methods of distributed leadership as was noted in these comments. A mentor stated, "We defined together again, which is the role of the leader as a manager and which is the role of the mentor as a sparring partner". (Process follow-up by a mentor) 
Additionally, a director gave his/her point of view, "We have the same direction, and if I 'aim to take too much', the mentor returns me to the surface" (Process follow-up by a director).

Educators thought that they received the greatest and equal amount of support related to encouragement and commitment from both the director and the mentor. The support received from the mentor was related to structure, innovation and the orientation of working practices. The support given by the director was related to organization and approval: the educators did not experience receiving significant organizational support from the mentor. Power is in balance between the director and the mentor (Northouse, 2007).

Educators were not the only people to benefit from the mentor arrangement. Directors thought that the project supported pedagogical management. They noted that meetings with mentors at the research day care centres were particularly important. The mentors themselves also appreciated the benefit they derived from them and emphasized that guiding the development of working practices supported their official duties. They thought that it was "an excellent way to keep up to date on what is happening in the day care centres" (Process follow-up by a mentor).

\section{Distributed leadership between directors, contact persons and documenters}

In addition to the support provided by the mentor and director, day care communities receive assistance from contact people from each research day care centre. The contact people, who were amongst the educators from each day care centre, provided encouragement and installed faith in people when they were overcome by development fatigue. They also made sure that assignments related to the development of working practices were completed in time, and that all information concerning the project was distributed among all educators. In the contact persons' peer group, the participants brought up the subjects of discussion. As mentioned earlier, when developing 
distributed leadership in different forums, theoretical thinking as well as the role of communication is crucial (e.g., Gomez et al., 2006; 2010). Next quotations illustrate that discussions with other colleagues enlarge the perspectives of participants.

\begin{abstract}
After peer group meetings with other contact persons, we discussed matters concerning VKK-Metro with the leader. (Process follow-up by an individual)
\end{abstract}

I have learned a lot from the other contact persons. I have obtained new ideas for my own work, and I have learned to review the development work in our own day care centre from different perspectives. I have learned to reflect on my own work even more deeply than before. (Process follow-up by an individual)

For the documentation of the development project, a goal was set from the beginning of the process to produce a project publication. For this work, each day care centre selected two participant educators. They took part in the Document Writers' peer group. The aim of this group was to document the development of the working practices for distributing the results. Educators from each research day care centre participated in the regular meetings of the document writers' peer group.

\title{
Distributed leadership among the staff
}

One main goal of the project was to create a multi-administrative practice for the practical development of distributed leadership (Gunter et al., 2013). When all employees participated, they learned to share responsibilities and discuss ideas concerning the next steps of development. 
Distributed leadership as administrative practice in Finnish Early Childhood Education and Care

During the process of developing this distributed leadership, everyone had a role to play in achieving a common goal; this has been a great model. When the subject is children's participation, it is natural that the development begins from our own experience of workers' participation. During the project, the distributed leadership began to take shape; because this project had a very clear structure and a variety of roles: director, mentor, contact persons, and the document writers. (The interview of director)

Furthermore, the team members shared responsibility for the project and thereby the expression of distributed leadership in everyday activities is clear from this comment, "Lilli has brought up the issue, which has hovered in the air, but which had not yet been taken up, in other words. Mary has raised the issue with the supervisor" (Process follow-up by a team). In Halttunen's study (2009), distributed leadership becomes evident especially through the different responsibilities shared among the educators.

The participant educators had to work with not only their own team or director, but also with administrative personal in the collective meetings. In the next quotation, an educator gives feedback to the mentor and through this, realizes distributed leadership. As one individual noted, "I hoped that the instructor would intervene more strongly so that all of our employees really would participate and express their opinions" (Process follow-up by an individual).

During the development of practices, there were reflective discussions about the planning and realization of the project, as is shown in the following quotes. The latter quote illustrates how another person can help to deepen the reflective level of thinking (see Ojala et al., 2011). 
Distributed leadership as administrative practice in Finnish Early Childhood Education and Care

Initially, the participant was always the same, but when this policy was assessed, it was found that members may want to change, as these meetings were inspiring, and brought the process forward, simply by sharing success stories and a variety of instruments, which began to emerge. (The interview of a director)

With the help of our mentor, we considered the reflection more deeply. We practised reflection together, which was very useful. The mentor knew how to analyse the reflection and guided us. (Process follow-up by a team)

These quotes illustrate the results of expressing different views in a dialogical debate, which is a key element in distributed leadership and a requirement for critical feedback that moved the development onward (see Gomez et al, 2006; 2010).

\section{Distributed leadership between research and participant}

Researchers at the University presented the research about this subject, and trained staff to reflect on their own work. Afterwards, the mentors supported the staff of their mentor-day care centres to implement the knowledge that they had received in the schooling.

[After a school day about children's' participation, carried out by researchers, ] we discussed our observations by means of participation. Groups had thought about how to increase the participation of children in their activities. Two groups in turn, presented their plans and experiences. As a mentor, I navigated the debate on participation levels. I think the discussion was very professional and development was observed. (Process follow-up by a mentor) 
Distributed leadership as administrative practice in Finnish Early Childhood Education and Care

Just such a combination of research and development is needed" and "This is the best part of VKK-Metro's function. (Teacher's feedback)

As Gomez et al. (2010) stress when referring to equality and fostering interaction between agents, there is a need for transformative knowledge between researchers and social actors. Early Childhood Education Master's students trained day care staff in the various day care centres during their practical training. One of the student's commented as follows:

We discussed the situations in which we were observing the children and noted how important it was that we did not rely on only one observation of the child. However, every teacher in the group made his or her own observations and then everyone discussed them. I will bring my own opinion to be heard, but at the same time, it is possible for me to gain new insights. ... We also spoke about the place and role of the adult, the circumstances in which adults are needed and in what circumstances they can withdraw a bit. (A student's learning diary)

\section{Distributed leadership among the highest administrative levels}

The members of the highest administration of early childhood education in the municipalities were also strongly connected to and motivated by the development process. They had monthly meetings in which guidelines of development and research were planned, issues from the field were discussed, and an understanding of the processes of the development project was shared.

In general, the steering group members were very interested in the study and wanted to know the results of analysis as soon as possible. It felt good when they were discussing how to disseminate the research findings in their own municipalities and applied themselves to 
Distributed leadership as administrative practice in Finnish Early Childhood Education and Care

study how the issues dealt with in day care could be utilized in the development throughout the region. However, sometimes it was noted that even those people who did not have a research-oriented expertise, wanted to tell researchers what kinds of research questions should be asked. (The interview of a researcher)

The process of sharing goals (Spillane et al., 2004) between the administrative level workers and the field workers level was new to all and therefore it will take some time for the processes to become embedded. The feelings about the meetings that included members of the highest hierarchical level were not always positive. According to one mentor, "In the steering group, I drew attention to a certain hierarchy [in the group]. In general, the speakers set out the issues to which the participants then listened and their issues were debated".

The participant day care centres' mentors and directors also met different stakeholder groups in their own municipalities and through them problems and innovations from the field were forwarded to the people at the administrative level. One of the mentors described her experiences with three different directors from the highest level of the organization. She describes how the information from the steering group reached her.

Because I worked for three different early childhood education directors, I can share my perspective. During the three-year project period, these three different leaders have managed the project in very different ways. The first director withheld information (from the steering group) and I did not even know what was going on in the project (outside the day care centre where I acted as a mentor). The next leader shared responsibility and my role grew surprisingly large. For example, the flow of information between us went particularly well. At this point, the leadership was distributed. The third director's leadership style was 
Distributed leadership as administrative practice in Finnish Early Childhood Education and Care something in between the first two. .. . The amount of the control, of course, affects your passion and the way you do your work. (The interview of a mentor)

In the previous quotation, the different power positions and different styles in the use of power become evident. It is the same in the next, where the power is exercised through control (Woods et al., 2004). In the cities with thousands of employees and many hierarchy levels, the culture cannot be changed via one project. As the next quotation illustrates, the project staff had to adapt to the different cultures in different cities.

Sometimes I felt frustrated when I had to ask the municipal authority for permission to ask for the assistance of experts on the lower hierarchy level. It took time and slowed down my work. In my own work at the University, I was used to the fact that I could ask for help wherever I wanted to. (The interview of a researcher)

Distributed leadership places many demands on those in leadership positions. There may be questions about who actually has permission to use power. One of the mentors described misunderstandings because of this ambiguity of power:

Maybe the city officials outsourced the designing to the project staff, which in turn, did not have a sufficient mandate to act. The temporary financing, the rush to get results to the report stage, and the feeling of jumping onto a moving train probably irritated everyone. (The interview of a mentor)

On the other hand, the participants on the administrative level also found themselves empowered to engage with the issues and discussion topics at the field level of early childhood education. This 
quotation by a mentor in the process follow-up summarizes administrative staffs' new consideration of everyday life in the day care centres, "[It was] an excellent way to keep oneself up to date on what is happening in the day care centres".

\section{Discussion}

High quality early childhood education requires the constant development of educational administration and ECEC practices. In the process, professionals of ECEC share ideology of the development and enhance this with reflective practices (Heikka et al., 2011; Venninen et al., 2012) as has been shown in this research. This ideology became visible during the development process, but it required the attitude of openness that was built upon trust and shared responsibilities. New perspectives about daily work in the day care centre were created by sharing observations and ideas with others. Educators who participated in the VKK-Metro project learned that development was not some extra duty directed from an upper hierarchy level, but a process that supported their professional development and distributed leadership not only at team levels, but also between the administration and the staff of ECEC. Discussion about development itself is not enough; development also requires efforts to implement concrete changes in practical work, where the role of director and the new distributed leadership practices were essential.

Two important issues, both raised by the developers, became important components of the development process. First, development should originate with the starting points of each participant educational community. Previously, a third party, such as the University, had defined the theme that was to be developed. Our results indicate that the development was more effective when the participants were charged with solving the problems they themselves had identified (see 
Spillane et al., 2004). Another leading thought of almost equal importance concerns progress via small steps. This idea was adopted at every level of municipal early childhood education, from the day care centres' educators to higher administrators. Through research evidence-based dialogue with the participant, it turned out that the results of developing working practices will not become apparent until they have been sufficiently ripened in joint discussions and in educators' thoughts (see Venninen et al., 2012). With the highlighted developmental idea, it became possible to obtain the 'permission' to focus on deepening the development in a peaceful atmosphere (see also, Belbin, 2000).

During the development project, the key elements in the pedagogical development of day care in light of distributed leadership were framed (Venninen et al., 2012) and are summarized in the following: 1. "Educators, researchers and administrators are all involved in the shared development of working practices. Students in the field also take part in development." Many results through the authentic quotations from participants prove that these principles were realized in our project. 2 . "Research, development and practical work support one another." The results indicate the benefit that research and distributed leadership provide in the development of practical work. Indeed, it takes time to familiarize staff with this new method instead of the methods of developing work practices through the feelings of each educator. 3. "Openness, transparency, respect for all parties and appreciation of their work are emphasized in action." Regardless of the many difficulties that occurred during the process, the shared work atmosphere became more optimistic and the respect between the groups that represented different organizational levels became more visible.

In this study, it became evident that on the highest levels of the organizations, the distributed leadership was not achieved as well as on the lower levels. In the transformative practice (Freire, 1998), all participants have the right to offer arguments by using their own speaking style. 
Referring to Spillane et al. (2004), we think that the shared perspective of the steering group concerning the practices of debates was not yet clear. The meetings were mainly conducted in the same manner as they had been conducted prior to the development project. This is the challenge for development projects in future.

In this study, distribution of leadership seemed to be realized better among the participants on the lowest and the middle hierarchical levels. Educators at the field level of ECEC thought that their efforts had been paid attention to and they received support from directors, administrative mentors, and the researcher for their development process. Directors and mentors viewed distributed leadership as a good way of development practices and brought out the role of staff as important agents in the development process. As Lunn and Bishop (2002) state, educators with a shared consensus about pedagogical practices were strongly in favour of the distribution of leadership. The consensus in this research was multi-voiced and formed with inclusive development practices. Enhancement of everyday practices was an on-going process, where shared views of different actors working as a team were in reflective interaction and could produce new participatory opportunities for developing both administrative culture and educational practice.

Our study shows, that there is a consensus to reduce the strong, central normative administrative control and emphasize staff expertise, guidance and counselling. This supports the planned changes in administration culture (Ruokolainen \& Alila, 2004). When doing this, administrative actors and educators at day care centres are willing to support activism and transformations. Even though participants confront problems, it is their shared responsibility to solve them. In this process, thoughts on critical communication are accepted and used. Instead of trying to make radical innovations, leaders should use a basic strategy to progress step-by-step respecting each other's opinions and voices. Our results could demonstrate that a social-critical approach was adopted 
especially at the low- and middle-hierarchical levels and old management methods were questioned and changed in shared interaction.

\section{References}

Ackerman, D. (2006), "The costs of being a child care teacher: Revisiting the problem of low wages. Educational Policy, 20, (1), 85-112.

Belbin, R.M. (2000) Beyond the Team. Oxford: Butterworth-Heinemann.

Bickmore, K. (2001). Student Conflict Resolution, Power "Sharing" in Schools, and Citizenship Education, Curriculum Inquiry 31, (2), 137-62.

Brown, A. L., \& Champione, J. C.(1994). Guided discovery in a community of learners. In K. McGilly, (Eds.) Classroom lessons; Integrating cognitive theory and classroom practice, 229-270. Cambridge, MA: MIT Press.

Bryant, M. (2003) Cross-Cultural Perspectives on School Leadership: Lessons from Native American Interviews, in N. Bennett, M. Crawford, and M. Cartwright (Eds.) Effective Educational Leadership, pp. 216-28. London: Paul Chapman.

Burke, C.S., Sims,D.E, Lazzara,E.H. \& Salas, E, 2007. Trust in leadership. A multi-level review and integration. The Leadership Quarterly 18(6), 606-632. 
Corter, C. \& Pelleter, J. (2010). Schools as Integrated Service Hubs for Young Children and Families: Policy Implications of the Toronto First Duty Project. International Journal of Child Care and Education Policy, 4(2), 45-54

Dalli, C. (2008). Pedagogy, knowledge and collaboration: towards a ground-up perspective on professionalism. European Early Childhood Education Research Journal 16(2), 171-185.

Ebbeck, M. \& Waniganayake, M. (2003). Early childhood professionals: Leading today and tomorrow. Sydney: McLennan \& Petty.

Freire, P. (1998). Pedagogy offreedom, Ethics, democracy and civic courage. Lanham, MD: Rowman \& Littefield.

Gananathan, R. (2011). Implications of Full Day Kindergarten Program Policy on Early Childhood Pedagogy and Practice. International Journal of Child Care and Education Policy, 5(2), 33-45.

Gomez, A., Racionero, S. \& Sorde, T. (2010). The years of critical communicative methodology. International Review of Qualitative Research, 3(1), 17-22.

Gomez, A., Latorre, A., Sanchez, M. \& Flecha, R. (2006). Metodologia communicativa critica [Critical communicative research]. Barcelona: Hipatia.

Gunter, H. E. (2012). The field of educational administration on England. British Journal of Educational Studies, 60(4), 337-356.

Gunter, H., Hall, D. \& Bragg, J. (2013).Distributed Leadership: A Study in Knowledge Production. Educational Management Administration \& Leadership, 3, 555-580. 
Habermas, J. (1987). The theory of communicative action. V.2. Lifeworld and system: A critique of functionalist reason. Boston, MA: Beacon Press.

Hackman, M.Z. \& Johnson, C.E. (2004). Leadership: a communication perspective. 4th Ed. Long Grove IL: Waveland Press, Inc.

Heikka, J. \& Waniganayake, M. (2011). Pedagogical leadership from a distributed perspective within the context of early childhood education, International Journal of Leadership in Education: Theory and Practice, 14(4), 499-512

Heikka, J., Waniganayake, M. \& Hujala, E. (2013). Contextualizing Distributed Leadership within Early Childhood Education: Current Understandings, Research Evidence and future Challenges. Educational Management Administration \& Leadership 41(30), 30-44.

Karila, K. (2010). A Finnish viewpoint on professionalism in early childhood education. In C. Dalli \& M. Urban (Eds.) Professionalism in Early Childhood Education and Care. International Perspectives. New York: Routledge.

Leinonen J. \& Venninen, T. (2012). Designing learning experiences together with children. Procedia: Social and Behavioral Sciences. 45, 466-474.

Lunn, P. \& Bishop, A. (2002) Nursery teachers as leaders and managers: a pedagogical and subsidiarity model of leadership. Research in Education, 67, 13-22.

McNiff, J. \& Whitehead, J. (2006). All you need to know about Action Research. London: Sage. 
Mehra, A., Smith, B.R., Dixon, A.L. \& Robertson, B. (2006). Distributed leadership in teams: The network of leadership perceptions and team performance. The Leadership Quarterly 17(3), $232-245$.

Mehra, A., Smith, B.R., Dixon, A.L. \& Robertson, B. (2006). Distributed leadership in teams: The network of leadership perceptions and team performance. The Leadership Quarterly 17(3), $232-245$.

Nonaka, I. \& Takeuchi, H. (1995). The Knowledge-Creating Company. How Japanese Companies Create the Dynamics of Innovation. New York: Oxford University Press.

Northouse, P.G. 2007. Leadership: theory and practice. 4th Ed. Thousand Oaks, CA: Sage.

O’Connor, P.M.G. \& Day,D.V. (2007). Shifting the emphasis of leadership development. From 'me' to 'all of us'. In J.A. Conger \& R.E. Riggia (Eds.) The practice of leadership. Developing the next generation of leaders. San Francisco: Jossey-Bass, 64-86.

Ojala, M. \& Venninen, T.(2011). Developing reflective practices for the day care centres in the Helsinki Metropolitan Area. Reflective Practice 12, (3), 335-346.

Ojala. M. (2010). Developing multicultural early childhood education in a Finnish context. International Journal of Child Care and Education Policy, 4, (1), 13-22.

OECD (2006), Starting Strong II: Early Childhood Education and Care, OECD, Paris. 
Rodd. J.(2004) Leadership in early childhood. The pathway to professionalism. UK: Open university press.

Ruokolainen, R \& Alila, K. (Eds.) (2004) Publication of the development project on quality management and steering in early childhood education and care. Publications of the Ministry of Social Affairs and Health, Helsinki: 2004:6.

Sammons, P. (2010) The EPPE Research Design: an educational effectiveness focus. In: Sylva et al. (Eds.), Early Childhood Matters: Evidence from the Effective Pre-school and Primary Education Project, London/New York: Routledge.

Schein, P. (1985). Organizational Culture and Leadership. London: Jossey-Bass.

Slavin, R.E. (2002). Evidence-Based Education Policies: Transforming Educational Practice and Research. Educational Researcher. 31(7), 15-21.

Spillane, J.P. (2005). Distributed Leadership. The Educational Forum, 69(2), 143-150

Spillane, J.P., Halverson, R. \& Diamond, J.P. (2004). Towards a theory of leadership practice: a distributed perspective. Journal of Curriculum Studies 36(1), 3-34.

Sylva, K., Melhuish, E., Sammons, P., Siraj-Blatchford \& Taggart, B. (Eds.) (2010). Early Childhood Matters. Evidence from the Effective Pre-school and Primary Education project. Routledge, London/New York. 
Suomalainen Lapsi [Finnish Child] (2007). Statistics Finland: Helsinki.

Technology and the New Professional Teacher: Preparing for the 21st Century Classroom (1997). A report of an NCATE Task Force on Technology and Teacher Education.

Taguma, M., Litjens, I. \& Makowiecki, K. (2013). Quality matters in early childhood education and care: Finland. Paris: OECD. DOI: 10.1787/9789264173569-en

Tse, H.H.M., Dasborough, M.T. \& Ashkanasy, N.M. (2008). A multi-level analysis of team climate and interpersonal exchance relationships at work. The Leadership Quarterly 19(2), 195-211.

Venninen, T., \& Leinonen, J. (2013). Developing children's participation through research and reflective practices. Asia-Pacific Journal of Research in Early Childhood Education. 7(1), 31-49.

Venninen, T., Leinonen, J. Ojala, M. \& Lipponen, L. (2012). Creating Conditions for Reflective Practice in Early Childhood Education. International Journal of Child Care and Education Policy. $6(1), 1-15$.

Woods, P., Bennett, N., Harvey, J.A. \& Wise, C. (2004). Variabilities and Dualities in Distributed Leadership. Findings from a Systematic Literature Review. Educational Management Administration Leadership, 32(4), 439-457. 